\title{
HIPNOSE, SINGULARIDADE E DIFICULDADES DE AMAMENTAÇÃO: UM ESTUDO CLÍNICO ${ }^{1}$
}

\author{
Maurício da Silva Neubern*
}

\begin{abstract}
RESUMO. Por meio de um breve estudo de caso, o presente trabalho busca ilustrar a construção de processos individualizados de sugestão hipnótica para uma jovem mãe que possuía dificuldades em amamentar seu bebê. Após a apresentação do caso, o trabalho centrase em três eixos de interpretação dos processos sugestivos que estiveram presentes na condução da sessão hipnótica: um primeiro voltado para os sentidos físicos, o segundo para o uso de metáforas envolvendo o leite e o terceiro para formas de redefinição sobre a competência da jovem como mãe. Nesses três eixos busca-se destacar a importância de que as sugestões hipnóticas contemplem a singularidade da mãe, contemplando suas emoções, sentidos e significados particulares. Por fim, o trabalho é concluído ressaltando a perspectiva de que a necessidade de mais pesquisas qualitativas deva consistir no reconhecimento da clínica como campo de pesquisa de modo que seja possível contemplar processos subjetivos presentes nas relações hipnóticas como o transe, a comunicação, a linguagem, a simbolização, as emoções e as construções de sentido.
\end{abstract}

Palavras-chave: Hipnose; singularidade; dificuldade de amamentação.

\section{HYPNOSIS, SINGULARITY AND BREAST-FEEDING DIFFICULTIES: A CLINICAL STUDY}

\begin{abstract}
Through a brief case study, the present article aims at elucidating the forming of individualized processes and the hypnotic suggestions for a young mother who had difficulties breast-feeding her child. Right after the presentation of the case, this work focuses on three axis of interpreting the suggestive processes which had been present in leading the hypnotic session: A first dealing with physical senses, a second dealing the use of metaphors involving the milk itself, and a third dealing with the forms of redefining the role of the young woman as a mother. Within these three axis, It is worth mentioning the how important it is for the hypnotic suggestions to take into account the singularity of the mother, considering her emotions, senses, and private meanings. Lastly, this work concludes by highlighting the outlook on the fact that the need for more qualitative research must acknowledge clinical practice as a research field in a way to entail subjective processes present in hypnotic relations such as trance, communication, language, symbolization, emotions, and the forming of senses.
\end{abstract}

Key words: Hypnosis; singularity; breast-feeding difficulties.

\section{HIPNOSIS, SINGULARIDAD Y PROBLEMAS DE AMAMANTAMIENTO: ESTUDO CLÍNICO}

RESUMEN. Por medio de un breve estudio de caso, el presente trabajo intenta ilustrar la construcción de procesos individualizados de sugestión de hipnosis de una madre joven que tenía dificultades para amamantar su bebé. Después de la presentación del caso, el trabajo se concentra en tres dimensiones de la interpretación de los procesos de sugestión que se hicieron presentes en la conducción de la terapia de hipnosis: el primero, dirigido para los sentidos físicos; el segundo, para el uso de metáforas que incorporan la leche, y el tercero, para formas de redefinición de la competencia de la joven como madre. En esas tres dimensiones se intenta resaltar la importancia de que las sugestiones de hipnosis lleven en cuenta la singularidad de la madre, contemplando sus emociones, sus sentidos y sus significados particulares. Por último, el trabajo concluye resaltando la perspectiva de que la necesidad de más investigaciones cualitativas debe reconocer a la clínica como un campo de investigaciones, de modo que sea posible contemplar procesos subjetivos presentes en las relaciones hipnóticas como el trance, la comunicación, el lenguaje, la simbolización, las emociones y las construcciones de sentido..

Este artigo deriva de projeto institucional do autor junto ao Centro Universitário de Brasília (2008-2009). Tal projeto foi aprovado pelo Comitê de Ética da Instituição e todas as medidas sobre ética com sujeitos humanos foram cumpridas.

Doutor em Psicologia. Professor Adjunto do Departamento de Psicologia Clínica, Instituto de Psicologia, Universidade de Brasília-UnB, Brasil. 
Palabras-clave: Hipnosis; singularidad; problemas de amamantamiento.

A literatura corrente sobre hipnose é dominada por perspectivas nomotéticas, marcadas por forte teor instrumentalista, pela busca do conhecimento de padrões gerais de resposta de sugestionabilidade e pela mensuração de determinadas respostas (Nash \& Barnier, 2008). Nesse sentido, os estudos voltados para o uso da hipnose na amamentação tendem a investigar o tema sob diferentes enfoques, mas na mesma perspectiva generalista. Enquanto alguns se centram sobre os efeitos químicos da hipnose no leite (Berthold, 2004; Cepicky, Pecena, Roth, Stroufova \& Sosnova, 1995), há os que enfatizam o uso de escalas e protocolos (Montgomery \& Hale, 2006), os que se voltam para sua eficiência como uma terapia complementar (Ayers, 2000; Duddridge, 2002; Tiran \& Chummun, 2004) e ainda os que focam o uso dessa modalidade terapêutica por parte dos profissionais de saúde (Raysler, 1999; Tiran, 2005). Semelhantes perspectivas, tipicamente ligadas a uma ótica médica, são úteis na medida em que fornecem informações gerais sobre o fenômeno, podendo situá-lo dentro da compreensão da população de sujeitos que acorrem aos serviços de saúde.

Entretanto, a dimensão subjetiva do processo de amamentação, que possui papel fundamental na ótica de certos autores (Arrais, 2005; Golse, 2003), fica completamente excluída de tais estudos, que se voltam para respostas e não processos, como para padrões gerais e não para a singularidade dos sujeitos. De acordo com a observação clínica (Arrais, 2005), a construção de sentido da mãe quanto a seu bebê é afetada, dentre outros processos, por sua história de vida, pelas pressões sociais que recebe, por seus projetos quanto à criança, pela forma como se deu sua gravidez, pelas mudanças de diferentes ordens que daí surgiram, como pela rede de relações que a mãe estabeleceu, inclusive com sua família. Sendo assim, a integração de múltiplos processos presentes na amamentação de uma criança remete a uma singularidade que não se dá por meio de um simples somatório de variáveis nem pode ser contemplada por estudos nomotéticos, voltados para a obtenção de respostas gerais.

Semelhante problema traz à tona a necessidade de uma pesquisa individualizada, que contemple as características singulares não só da pessoa, como também de seu contexto (Erickson, 1983; 1986; Erickson \& Rossi, 1979; Zeig, 1994). Assim, o ato aparentemente simples da amamentação possui múltiplas articulações que envolvem a mãe e o bebê e precisam ser contemplados num processo hipnótico: entre ambos, ocorre uma comunicação intensa, múltipla e profunda que envolve tanto a dimensão sensória e emocional, como os primeiros registros simbólicos da subjetividade da criança (Golse, 2003). Além disso, tal relação é perpassada por uma série de mensagens de ordem social e cultural, cuja influência é marcante na construção dos processos subjetivos em que a mãe e a criança tomam parte. Por tais razões, concebe-se que o processo terapêutico e hipnótico da amamentação, ao invés de se estabelecer a partir de sugestões padronizadas, deve contemplar a singularidade de cada pessoa, com suas expressões próprias, suas formas de comunicação e seus modos de construção de sentido que se integram a processos sócio-culturais diversos.

Em vista desse quadro, o presente trabalho propõe um breve estudo de caso com o intuito de ilustrar a construção de processos individualizados de sugestão hipnótica que visem contemplar a singularidade de uma pessoa. Trata-se de uma jovem mãe que solicitou ajuda hipnótica em função de suas dificuldades em amamentar seu bebê recém-nascido, mostrando-se muito irritada, insegura e incompetente na situação. $\mathrm{O}$ trabalho será desenvolvido buscando destacar que a construção das induções possuiu estreita relação com os processos subjetivos da jovem, seja em termos de seus sentidos físicos e suas formas de comunicação, seja em termos de suas construções emocionais e de sentido (Erickson, 1980). A interpretação, fundamentada em referenciais clínicos e qualitativos (Gonzalez Rey, 2005; Neubern, no prelo) será desenvolvida em torno de três eixos de sugestão que ocorreram, na maior parte do processo, de forma simultânea. Deve-se destacar ainda que as ditas sugestões, conduzidas pelo pesquisador principal do trabalho, quem efetivou o atendimento da jovem, serão mostradas apenas em alguns de seus momentos, em razão dos limites de espaço.

\section{O CASO}

Maria Luíza, 21 anos, estudante de arquitetura, havia mencionado ao pesquisador, numa conversa informal, que estava com dificuldades em amamentar seu bebê. Ela se mostrava muito cansada e dizia que há noites não dormia bem. Então, aceitou o convite do pesquisador para uma sessão experimental de hipnose, em seu grupo de pesquisa, formado pelo pesquisador e 
4 estagiários de psicologia. Era sabido que a criança havia vindo de uma forma inesperada, pois a jovem ainda não havia se casado com seu namorado, nem concluído sua faculdade. Além disso, era comum que sua família a criticasse, como se ela não soubesse cuidar de seu bebê, principalmente quando ele chorava. Em meio a tal dinâmica, o choro do bebê a tornava mais irritadiça, colocando-a na sensação de incompetência e paralisia, o que se agravava ainda mais com as críticas de sua família. Assim, embora produzisse leite, ele não fluía na amamentação e sua irritação aumentava ainda mais com as mordidas do bebê, tentando sugar seu seio. Porém, ao ouvir falar do grupo de pesquisa de hipnose, ela se interessou pela idéia e resolveu participar da sessão, dizendo estar disposta a qualquer trabalho para melhorar seu problema. Em um tom jocoso acrescentou: "quero sair de lá como aquelas vacas leiteiras que é só apertar assim que jorra aquele leite!” Assim, ela compareceu à sessão no dia marcado na presença do grupo de pesquisa. A sessão com Maria Luíza consistiu num momento de pesquisa clínica e qualitativa (Gonzalez Rey, 2005; Neubern, no prelo) que, além de ser terapêutica para a jovem, buscando atender suas demandas na medida do possível, procurou ilustrar para o grupo como se constróem as sugestões hipnóticas para um caso particular.

\section{INTERPRETAÇÃO INICIAL SOBRE O CASO}

Diante dessas circunstâncias, o pesquisador resolveu evitar uma entrevista mais detalhada sobre o cenário subjetivo de Maria Luíza, pedindo a ela que se expressasse até onde se sentisse confortável diante do grupo de pesquisa. Além de oferecer-lhe um papel ativo no trabalho, exercendo controle sobre as informações, o que é importante tanto para a hipnose (Erickson, 1985), como para a pesquisa clínica (Gonzalez Rey, 2005), havia duas razões básicas nesta forma de abordar o sujeito. Por um lado, para preservar sua privacidade, já que ela estaria diante de um grupo e, como tal, isso poderia fazer com que se sentisse exposta ou pressionada, o que já acontecia em seu cotidiano familiar. Esse risco realmente existia já que algumas pessoas do grupo eram conhecidas suas de outros contextos, apesar de os membros do grupo relatarem não possuir proximidade afetiva com a jovem. Por outro lado, era também importante demonstrar que determinadas intervenções não carecem de uma avaliação muito detalhada para levarem a um bom resultado que, ao mesmo tempo, preserve a integridade do sujeito e ofereça propostas eficientes para suas demandas (Erickson \& Rossi,
1979). Em suma, tais circunstâncias foram relevantes para demonstrar as possibilidades de construção de uma pesquisa clínica na própria situação de campo típica dos contextos de saúde atuais, de maneira a conciliar diferentes exigências que perpassam o cenário de investigação. Assim, embora exista o risco da exposição do sujeito diante de profissionais e estudantes, é possível minimizá-lo oferecendo-lhe controle sobre as informações a serem passadas (onde ele decide o que, quando e como devem ser expresso) e por meio da utilização de técnicas indiretas, como metáforas e analogias, nas quais o trabalho se volta para um nível simbólico e não para informações literais sobre o sujeito (Erickson, 1983; 1985). Ao mesmo tempo, foi possível demonstrar que, apesar de limitações como escassez do tempo, em certas circunstâncias, é possível intervir de maneira a produzir informações de pesquisa $\mathrm{e}$ atender as necessidades do sujeito.

Sendo assim, numa primeira aproximação interpretativa (Zeig, 1994; 2006), foi possível utilizar as próprias informações trazidas pela jovem naquela única conversa informal. Percebeu-se que um dos pontos importantes era sua própria audição acurada que, em meio a uma dinâmica de acusação familiar, contribuía para uma profunda irritação diante do bebê, como se seu choro fosse amplificado e se somasse a todo o coro de acusações que já sofria de sua família. Também foi possível notar que sua sensação de paralisia se relacionava a uma dinâmica em que se sentia profundamente pressionada pela família, como se seu espaço privado e sua própria subjetividade fossem freqüentemente invadidos, levando-a a se sentir desqualificada. Nessa perspectiva, o pesquisador elaborou algumas estratégias que pudessem contemplar a situação de Maria Luíza de modo a fazer com que sua competência como mãe fosse retomada e o processo de amamentação pudesse fluir normalmente. Não se buscou, portanto, uma intervenção que destacasse a dinâmica relacional de críticas e acusações da família, mas apenas os recursos que apontassem para seu potencial como mãe que poderiam também ajudá-la a não tomar parte nesse tipo de transação.

Os recursos hipnóticos adotados foram profundamente influenciados pela noção de comunicação indireta (Erickson \& Rossi, 1979; 1980). Tais técnicas, que incluem metáforas, analogias, jogos de palavras, consistem em estruturas lingüísticas que são oferecidas ao sujeito em transe que não lhes impõem um conteúdo específico, mas permitem que eles mesmos construam suas associações dentro de determinado tema que é proposto pelo pesquisador. $\mathrm{O}$ 
que caracteriza essa forma de comunicação é sua ênfase em recursos, geralmente inconscientes, que o sujeito não confere valor ou mesmo desconhece, mas que podem vir a ser de grande valia para um processo de mudança mais amplo (Neubern, 2004). Erickson (1980) considerava que as técnicas baseadas na comunicação indireta tendem a ser mais eficazes, já que é o sujeito quem se apropria de seus próprios recursos e potenciais e os utiliza a favor de suas próprias demandas e necessidades, sendo que as intervenções do terapeuta não são mais que desencadeadores desses processos ${ }^{2}$. Desse modo, o pesquisador desenvolveu, durante o transe de Maria Luíza, três eixos de intervenção que foram trabalhados simultaneamente, visando objetivos específicos ligados a suas demandas ${ }^{3}$.

\section{PRIMEIRO EIXO HIPNÓTICO - AFINANDO OS OUVIDOS}

Um dos pontos que chamou a atenção do pesquisador, inicialmente, foi a ênfase que Maria Luíza conferiu à escuta do choro de seu bebê. Nesse sentido, o pesquisador compreendeu que era necessário que tal processo fosse concebido como uma possibilidade para melhora de seu relacionamento com o filho ao invés de um problema sem solução. Em outras palavras, era preciso que sua sensibilidade auditiva fosse inserida no contexto terapêutico como uma habilidade a ser utilizada favoravelmente pela jovem (Erickson, 1958). Assim, o pesquisador teceu as seguintes sugestões:

1. "E você, Maria Luíza, escuta os sons lá de fora ... essa construção em que os homens trabalham e quebram as paredes ... e esse barulho pode ser irritante pra muita gente ... mas você pode acompanhar um pouco essas batidas e deixá-las vir até você ... e notar que elas chegam até você e vibram em seu corpo ... e você pode ficar com elas ou deixá-las ir embora.... e você também pode escutar os sons dessa sala, seus colegas que

2 O que difere essa abordagem da hipnose clássica, na qual o terapeuta faz prescrições diretas para que o sintoma suma ou algum fenômeno aconteça. Isso favorece a aparição de resistências, o que já foi apontado desde a época de Freud (1905).

3 Não será possível um detalhamento preciso sobre o uso das técnicas e para tanto recomendamos Erickson e Rossi (1979). Também se deve frisar que os relatos sobre as técnicas aqui descritas estão apenas sínteses por razões de espaço, sendo, portanto, apenas ilustrações. Os grifos significam uma ênfase maior na voz do pesquisador. anotam nossa sessão e mexem nos cadernos ... e você pode escutar a minha voz e fazer o que quiser com ela ... e você também pode escutar os sons de sua respiração e perceber como é agradável respirar."

2. "E agora, você pode aproveitar esse momento em que seu corpo está repousado, em que você sente seu peso sobre esta poltrona, e sua respiração flui e ir pra onde você quiser ... talvez você escute o choro de seu filho e possa acompanhá-lo também de uma forma bem tranqüila ... e estudar um pouco este choro e notar que ele vem até você, mas você pode deixá-lo ir embora... e como é bonito olhar pra esse menino aí deitado, dormindo ... e eu não sei que música você ouviria agora ... indo pra algum lugar onde você queira estar ... talvez viesse até você aquela música do Djavan..."

Nesta breve seqüência, cabe destacar algumas características que visaram auxiliá-la a modificar sua forma de escutar o choro do filho. No primeiro momento, o pesquisador fez um movimento progressivo que abrangeu desde o som externo até os sons da própria respiração da jovem, de maneira a desfocar do incômodo exterior (veja-se a ênfase na palavra irritante), para uma sensação de tranqüilidade interna. Assim, foi passada à jovem a sugestão de que o ouvido poderia selecionar seu foco e, mais que isso, poderia sair de situações incômodas que estivessem a seu redor para se ater a processos internos de seu próprio mundo, aqui tranqüilizados pela respiração suave e pela agradável sensação de relaxamento que já era visível naquele momento. Outra mensagem importante referiu-se a sua possibilidade de acompanhar com seu pensamento os sons irritantes - o que lhe sugeriu uma possibilidade diferente da irritação, que foi a de observar com tranqüilidade esses estímulos. Dessa forma, ela acompanhou e percebeu que os sons chegavam a seu corpo, mas que ela possuía a opção de não se fixar neles, deixando-os irem embora, termo que é devidamente acentuado na voz do pesquisador.

Nesse sentido, a mesma seqüência se repetiu com relação ao choro do filho que tanto lhe trazia incômodos. Ela já estava em outra condição para poder recebê-lo (em um estado mais relaxado e tranqüilo) e poderia também aplicar o mesmo dispositivo: o de acompanhá-lo, deixá-lo tocar em seu corpo e, principalmente, deixá-lo ir embora. Ou seja, em outro contexto, ela possui a possibilidade de não se deter na irritação causada pelo choro e poderia se direcionar para viver outros tipos de experiência. $\mathrm{O}$ pesquisador completou a seqüência acrescentando novamente uma cena agradável - a de poder observar 
o bebê deitado - sem fazer qualquer menção a seu choro. Reforçando essa cadeia de sugestões, o pesquisador lhe propôs ainda, baseado num conhecimento prévio sobre seu gosto pela música, que seus ouvidos poderiam trazer também, para junto de sua experiência com seu filho, uma experiência muito agradável - a música de Djavan, cantor a quem ela tanto apreciava.

Sendo assim, se anteriormente sua narrativa era marcada pela irritação causada pelo choro do bebê, agora o contexto hipnótico proporcionava em sua experiência subjetiva uma série de pequenas mudanças. O choro não deixava de existir, nem a irritação; mas esta era qualificada de outra forma, como algo que pode ser liberado de sua experiência. Mas além do choro, as sugestões resgataram e ressaltaram experiências agradáveis de seu convívio com o filho, quais os momentos de relaxamento, de poder respirar bem, de observar o bebê dormindo e também de ouvir uma boa música. Em suma, novas experiências foram evocadas de sua própria subjetividade de maneira a lhe proporcionar um contexto de vivência mais rico e diversificado com seu filho.

\section{SEGUNDO EIXO HIPNÓTICO - O LEITE}

O leite aparecia como o representante inicial da queixa de Maria Luíza. Se seu médico lhe dizia que ele era produzido, ela se questionava sobre porque ele não fluía normalmente para seu filho no momento da amamentação. Assim, o pesquisador procedeu às seguintes sugestões hipnóticas.

1. "Eu me lembro, certa vez, assistindo ao Globo Rural de um fazendeiro que falava sobre a forma correta de ordenhar uma vaca... ele dizia que era importante para o animal que o peão se aproximasse com jeito ... de uma forma amistosa ... e pegasse em suas tetas com cuidado e com carinho ... alguns fazendeiros gostam até de colocar música clássica no estábulo ... e dizem que as vacas se sentem melhor e produzem mais leite ... e eu fico imaginando como deve ser interessante pra vaca ouvir essas músicas e $\underline{\text { se }}$ deixar envolver por ela ... ser tocada suavemente pela música..."

2. "E uma outra visão que é muito bonita, é a de $\underline{u m}$ simples copo de leite ... isso já pode abrir o apetite de muita gente ... porque é algo muito saboroso ... e talvez você possa se perguntar sobre como deve ser um balde de leite... ou uma banheira de leite ... mas deve ser muito bom mesmo uma piscina de $\underline{\text { leite }}$... e chegar à beira dela e olhar ... $\underline{\text { e você pode }}$ fazer o que quiser ... agora..."

Nesta seqüência de sugestões, há um primeiro momento em que o pesquisador retomou a necessidade de um contexto agradável para se conseguir algo - no caso a produção do leite. Ele aproveitou a piada da jovem, a de se tornar uma vaca leiteira, e construiu uma série de sugestões em que são ressaltadas algumas condições para que ela se sintisse bem e, assim, produzisse leite. É interessante notar que, a partir da piada, a jovem se identificou com a vaca, mesmo que de uma forma inconsciente, de maneira que as condições para que esta produzisse bem eram semelhantes àquelas que ela mesma precisava para que seu leite fluísse (Melchior, 1998). Outro ponto de identificação que as uniu foi a própria música, conforme enfatizado na voz do pesquisador: a música que tocou o corpo suavemente e trouxe uma sensação de bem estar. No caso ainda é enfatizado, como nas sugestões sobre os ouvidos, que ela poderia se deixar envolver pela música sendo tocada por ela.

Já a segunda sequiência apontou para um processo gradativo de produção do leite. Ela começou com um copo, onde foi acrescentada a sugestão de algo saboroso que abriu o apetite, associando à amamentação a dimensão prazerosa ligada ao leite. Esse prazer se repetiu em outras escalas e culminou com uma piscina de leite, que, em seu transe, a jovem relatou ter mergulhado e aproveitado bem. Portanto, se inicialmente o leite era associado à dúvida e a um bloqueio, ele passou a ser associado a um processo mais amplo, tal como simbolizado nas sugestões acima. Pela própria identificação com a vaca, foi possível lhe passar novamente a idéia de que a produção de leite estava ligada a boas condições, em que existia um contexto acolhedor, prazeroso e, às vezes, musical. Houve também outra característica importante que se referiu ao processo gradativo em que a sugestão foi construída. Inicialmente, sugeriu-se a visão de um copo de leite, associado à idéia de algo saboroso; em seguida, surgiu o balde e depois a piscina, ambos associados a algo prazeroso. Note-se que, nessa sequiência, a imagem do leite surgiu de modo gradativo e foi associada ao prazer, o que possibilitou desvinculá-la aos poucos de sua associação com o bloqueio, com a impossibilidade. Assim, com uma sugestão permissiva ao final - a de que ela poderia fazer o que quisesse para aproveitar o momento - a jovem se permitiu de ter opção diante das circunstâncias que vivia no transe e também de aproveitá-la. Não foi por acaso que, em seus relatos, ela descreveu ter mergulhado na piscina de leite, onde brincou e se divertiu bastante. 


\section{TERCEIRO EIXO HIPNÓTICO - RESGATANDO A COMPETÊNCIA}

O terceiro eixo hipnótico ocorreu na parte final da sessão e foi de grande importância, não só pelas redefinições que proporcionou, como também pela dinâmica da conversação. Maria Luíza alternou momentos de transe profundo e leve e, durante alguns momentos, demonstrou estar conversando de forma consciente, de olhos abertos, mas manifestando sinais típicos de transe (Erickson, 1952).

1) $P$ - "E, nesse momento, talvez você possa se lembrar de sua infância. Eu fico me perguntando do que você gostava de fazer na infância... como eram suas brincadeiras, o que você fazia pra se divertir, quais eram seus programas ... e como você sentia isso... porque a criança quando se diverte entra num mundo que é só dela, e surgem histórias, personagens, roteiros, seres ... e de fora não podemos entender muito ... mas ela sabe o que se passa ... e os adultos podem até olhar, mas são elas que entendem daquilo ...” ao pedir para relatar o que via, Maria Luíza respondeu - "Vejo a minha avó... estou na casa dela ...” P - "você vê sua avó, está na casa dela ... e como é isso pra você?" ML - "é muito bom. Eu adoro ir pra lá. Ela fica na cadeira de balanço e dorme. E eu fico brincando ao lado dela. Acho ótimo. Sei que ela está ali..." $\mathrm{P}$ - "E onde você sente isso no seu corpo?" ML - "Aqui, na altura do peito, da barriga também." P "Ok. Deixe essa energia aí, trabalhando em você, aproveite-a bem..."

2) Depois e algum tempo, Maria Luíza abriu os olhos, pondo-se a chorar. Dizia: "Isso tudo é muito difícil. Acho que não sou uma boa mãe..." $\mathrm{P}$ - "Ninguém está pronto pra ser pai ou mãe. Quem nos faz prontos pra isso são os filhos. E acho que você está aprendendo muito bem." ML - "Não, eu não sei cuidar de meu próprio filho. Ele chora e eu me irrito com isso... uma boa mãe não age assim." P - "Você se lembra de sua avó? Ela tinha um jeito diferente de cuidar, não? Não era de falar muito, mas estava ali do seu lado. E como isso era eficiente. Pra você funcionou muito bem, pois você sabia que podia contar com ela, que ela estava atenta a você." ML "É mesmo ... ela ficava ali e me passava muita segurança...” P - “O que ela diria pra você hoje?” ML - "Não sei, mas se ela estivesse aqui, não me pressionaria. Só a presença dela me daria segurança." $\mathrm{P}$ - "Isso é muito bom. E sabe que você tem outra coisa importante. Você sabe olhar pro seu filho, sabe observá-lo sim." ML - "Como assim?" P - "Foi você quem disse que descobriu que se começasse a dar banho pelos pés dele, ele não abria o berreiro e ficava tranqüilo. Olha só como você pôde descobrir isso? Isso é coisa de boa mãe. Você está indo muito bem em seu aprendizado. Continue olhando pra ele e deixe os outros dizerem o que quiserem. Você vai filtrar isso. Olhe pra ele... E tem uma tarefinha de casa. Você aceita?" ML - "Sim, o que é?" P - "Pegue uma foto de sua avó e leve-a sempre em sua bolsa. Olhe pra ela todos os dias e sempre que você sentir necessidade. Acho que isso vai lhe ajudar muito."

Esse trecho foi marcado por uma perspectiva de redefinição em que as sugestões visaram oferecer novos significados às situações descritas pelo sujeito, como também resgatar seus recursos (Erickson, 1985; Zeig, 2006). Trata-se de um processo particularmente útil quando o cliente se vê impregnado de idéias de incapacidade que o paralisam e o fazem sofrer, como era o caso de Maria Luíza. O primeiro momento deste trecho, em particular, possuiu um foco bastante voltado para a busca de experiências construtivas de cuidado na infância. É curioso notar que o início da sugestão regressiva destacou experiências prazerosas em si e a própria jovem acabou trazendo uma figura protetora, a avó, associada a essas vivências, provavelmente porque já estivesse muito ligada à sua própria demanda naquele momento - o cuidado. Quando se promove uma experiência desse tipo em que a demanda da pessoa é associada a algo construtivo e prazeroso de sua história, torna-se possível criar um contexto protetor que permita à pessoa lidar com processos mais sofridos de sua experiência, sem que ela se sinta tão ameaçada ou tenha que reviver alguma experiência violenta. Por tal razão, o pesquisador lhe sugeriu que deixasse a "energia" daquela emoção trabalhar em seu corpo e que ela se impregnasse disso. Também é importante destacar que o lugar onde se ancoraram tais emoções foram o peito e a barriga, partes do corpo muito associados à sua demanda de cuidado materno. Portanto, o primeiro momento aqui discutido se tornou uma espécie de preparação para que Maria Luíza pudesse avançar em seu processo terapêutico e, se possível, deparar-se com processos mais difíceis que a faziam sofrer, como realmente aconteceu.

Assim, o segundo momento mostrou, com certa clareza, a ambigüidade de sua experiência. Se, por um lado, ela havia mergulhado nas doces experiências com sua avó que cuidava dela de uma forma tão peculiar, por outro, ela abriu os olhos e retomou a pressão que havia sobre seu desempenho como mãe. Já se pôde observar aqui uma mudança significativa, pois, anteriormente, a pressão parecia ser hegemônica em sua experiência, sendo confirmada por seu nervosismo, sua irritação com a criança e sua incapacidade de amamentá-lo. Mas, o que se passou a seguir no diálogo com o pesquisador, foram processos 
que ressaltaram e colocaram em cena para a jovem elementos de cuidado que já existiam em sua história e que já estavam, de alguma forma, acontecendo na relação com seu filho. Note-se que a primeira fala do pesquisador, quando Maria Luíza já estava de olhos abertos, mas ainda mostrava sinais de transe, foi prudente ao ressaltar o aprendizado de um papel, de maneira a romper com a crença de que uma mulher se torna uma mãe zelosa e pertinente de forma repentina. Essa sugestão foi retomada ao final da fala do pesquisador, quando ressaltou que ela estva indo bem em seu aprendizado.

Em seguida, houve uma forma de sugestão que foi passada com o intuito de ampliar as possibilidades de uma palavra - o cuidado. Maria Luíza sentia-se acusada por não saber cuidar dentro de um modelo que lhe era oferecido - o da mãe perfeita, que jamais se irritava, que estava sempre feliz, que era sempre pertinente e que nunca errava quanto ao filho. Porém, a sugestão trazida possuía uma característica dupla: além de ampliar as possibilidades sobre as formas que existem de cuidado, ela estava enraizada em sua própria experiência, ou seja, a forma de cuidado inteligente e eficaz que sua avó exerceu com ela. Assim, tal sugestão, possivelmente, trouxe consideráveis impactos de mudança de sentido junto à jovem, uma vez que, além de lógica (existem muitas formas de cuidar), estava associada ao que ela mesma vivenciou e impregnada no seu corpo por suas próprias emoções.

Já ao final, houve outro conjunto de sugestões que complementaram e deram continuidade ao que foi até aqui discutido. Tratou-se de ressaltar que Maria Luíza possuía, de fato, uma forma de cuidar que já estava em desenvolvimento. Para tanto, o pesquisador se utilizou do sentido visual que apareceu algumas vezes nos relatos da jovem diante de seu bebê. Olhando para o filho, ela mesma havia descoberto uma forma confortável e tranquiila de lhe dar banho, uma forma que não o fazia chorar e se irritar. Desse modo, as palavras relativas ao olhar surgiram de diferentes maneiras, seja na interjeição do pesquisador, seja na sua prescrição de continuar olhando para o filho ou na própria prescrição de tarefas de olhar para a foto de sua avó. Em outras palavras, a palavra "olhar" ficou associada à descoberta, a uma habilidade de observação e a uma figura de apoio e cuidado muito significativa em sua vida, o que lhe permitiu a construção de novas associações sobre o tema.

\section{CONSIDERAÇÕES FINAIS - UM PROCESSO ARTESANAL}

Alguns dias após a intervenção, Maria Luíza procurou o pesquisador demonstrando estar satisfeita e alegre, já que estava dormindo melhor e a amamentação estava fluindo bem. Não se irritava mais com o choro da criança e sentia prazer em perceber que sua produção de leite estava boa. Casos como o dela, trazem à tona possibilidades práticas interessantes nos contextos de saúde, por várias razões, como por se tratar de uma intervenção breve, eficiente e que, nesta situação, dispensou o uso de procedimentos invasivos e medicamentos. Em suma, intervenções como esta aqui discutida aliam a consideração com o sujeito ponto comumente criticado pelos usuários nos serviços de saúde - e a praticidade - ponto tão ansiado pelos profissionais de saúde devido à intensa dinâmica de seus serviços. Obviamente, pelo que se observa na própria literatura sobre o tema, são necessários mais estudos qualitativos sobre intervenções dessa natureza, tanto em termos de seu funcionamento e possibilidades, como no que se refere à sua adaptação às próprias culturas de centros de saúde, clínicas e hospitais. Portanto, a praticidade, como a consideração ao sujeito, não devem servir de pretexto para que não exista a reflexão teórica.

Nessa linha de pensamento, o que se buscou refletir neste trabalho foi a dimensão singular da intervenção hipnótica num caso específico de dificuldade de amamentar. O estudo mostrou diferentes níveis de comunicação em que o pesquisador buscou construir sugestões específicas que contemplassem a singularidade da mãe que já apresentava considerável carga de sofrimento psíquico.

$\mathrm{O}$ primeiro eixo de construção das sugestões se caracterizou pelo uso dos sentidos físicos, o que consiste num procedimento corriqueiro na história clínica da hipnose (Erickson, 1986; Roustang, 1991). É possível considerar que os sentidos físicos consistem em momentos importantes da comunicação do sujeito com o mundo e os outros, pois ao mesmo tempo em que o conectam com o mundo externo são vias de subjetivação que permitem a construção de sentidos e emoções do sujeito quanto a um determinado tema. Assim, o choro do bebê associou-se a toda uma construção negativa de Maria Luíza sobre si e a maternidade de maneira que, toda vez que ocorresse, lhe mobilizava profunda irritação e sentimentos de incompetência. Entende-se que os procedimentos hipnóticos foram eficazes nesse processo por proporcionarem o rompimento de tal associação e também por favorecer ao sujeito novas formas de uso de sua audição, associadas à seleção de outros focos e ao prazer de outros estímulos. A qualificação dos sentidos físicos parece sugerir ao sujeito um movimento de atenção voltado para si mesmo, de maneira a proporcionar circuitos complexos de feed-back que possuem consideráveis possibilidades terapêuticas, tanto em termos psicológicos, como fisiológicos (Erickson, 1986; Melchior, 1998; Rossi \& Cheek, 1988). 
Já o segundo eixo, além do apelo sensorial acima discutido, tanto da música clássica como do visual sugerido pelo leite, trouxe também a comunicação pela via da metáfora, aproveitando a piada feita pela própria jovem - a vaca leiteira. $\mathrm{O}$ uso de figuras de linguagem, como metáforas, contos e analogias, quando ocorre dentro de determinadas condições, pode favorecer consideravelmente mudanças na construção de processos subjetivos de uma pessoa (Erickson, 1992; Erickson \& Rossi, 1979; 1980). Isso porque não se caracterizam por uma interpelação direta ou por uma ordem, mas pela transmissão sutil e indireta de mensagens que, em grande parte, não se tornam conscientes ao sujeito, mas mobilizam uma série de recursos favoráveis para a lida com determinada situação por ele vivida. Como o sujeito não se sente pressionado a uma resposta deliberada, ele tende a se sentir numa condição de conforto já que suas resistências não são ativadas e, assim, ele possui a opção de construir ou não associações sobre os temas veiculados pelas mensagens. A vaca leiteira sugerida pelo pesquisador consistiu numa figura de linguagem que trouxe mensagens diversas e interessantes para Maria Luíza para quem a doação de seu próprio leite estava inicialmente perpassada por sentidos negativos: ela trouxe o humor (pela própria forma jocosa com a qual a jovem se referiu a ela), remeteu a um contexto confortável e com regras corretas para a boa doação de leite, como também a tranqüilidade, conforto e prazer. Uma situação inicialmente tensa e perpassada pelo peso da pressão e das acusações passou a ser marcada por um contexto de leveza e conforto onde um animal produzia leite ao embalo de música clássica. A metáfora, portanto, pareceu funcionar como um conjunto complexo e integrado de mensagens que bombardeia de modo sutil e gradativo as construções negativas e incapacitantes do sujeito, ao mesmo tempo em que lhe ofereceu novas possibilidades de associação e sentidos sobre os temas a que se referia. Daí a necessidade de que ela fosse feita contemplando os sentidos, emoções e significados particulares do sujeito e que o pesquisador não explicasse o que pretendia para o paciente, já que as construções deste último eram o que realmente importavam para o processo.

O terceiro eixo, por sua vez, consistiu numa perspectiva de oferecimento de novas possibilidades de significação do sujeito para um determinado tema ou, simplesmente, as técnicas de redefinição (Erickson, 1985; Zeig, 2006). É comum que as situações de sofrimento impliquem em sensações de paralisação, incapacidade e incompetência alimentadas pelo próprio sujeito, como por seu meio social. Torna-se necessário, assim, que as intervenções terapêuticas possam oferecer possibilidades distintas e concretas e tomem as devidas precauções para não repetirem os padrões acusatórios e patológicos que já incidem sobre os sujeitos nos meios sociais em que se inserem (Neubern, 2001; 2005). Assim, ao invés de enfatizar as possíveis psicopatologias ou incapacidades da jovem mãe, o pesquisador procedeu a vários momentos de redefinição com o intuito de romper com a forte tendência de criação de expressões de incompetência que a acompanhava. No entanto, para isso, foi necessário que a construção da sugestão não se assemelhasse a uma fórmula simplista de pensamento positivo, mas acontecesse de uma forma lógica para o sujeito, que fosse razoável para ele de modo a lhe possibilitar a construção de saídas efetivas para seu problema. Note-se que, nessa mesma linha de pensamento, o pesquisador interveio utilizando os próprios relatos de Maria Luiza, qualificando-os de uma forma em que ela, até o momento, talvez ainda não tivesse percebido ou valorizado. Ao ressaltar sua habilidade em cuidar do próprio filho, observando e desenvolvendo uma forma mais agradável de banho para ele, ele destacou seu bom desempenho no aprendizado de cuidado materno, o que contrariou de forma lógica e consistente as construções de incompetência que desenvolvia sobre si mesma ${ }^{4}$. Ao se utilizar da figura da avó, que ela acabara de visualizar na hipnose, ele ressaltou seu modo distinto de um cuidado que ela mesma havia vivido, rompendo com a perspectiva de uma forma única e correta para a tarefa.

Por fim, pode-se ressaltar que os três eixos aqui discutidos consistem em processos sugestivos particularizados, situados num contexto relacional específico e voltado para um sujeito singular. A necessidade de mais pesquisas em tal direção não implica forçosamente na quantificação ou na busca de mais resultados empíricos, mas no desenvolvimento de possibilidades teóricas e clínicas que, numa relação dialógica com a prática, permitam a inclusão efetiva do singular tanto como noção epistemológica, como de uma necessidade prática do cotidiano (Neubern, 2006). Em outras palavras, é necessário que se busque compreender e conceituar processos de subjetividade que se articulam nas situações cotidianas, tanto da hipnose como das relações clínicas em geral, como se viu no caso aqui discutido. Noções como contexto, linguagem, comunicação, transe, simbolização, emoções e construção de sentidos merecem lugar de destaque para tais considerações. Para tanto, não é necessário que se busque respaldo em métodos quantitativos e experimentais, mas apenas que se reconheça que a prática clínica também se constitui como campo legítimo de pesquisa e reflexão,

\footnotetext{
Deve-se ressaltar que não se trata apenas de um argumento racional, mas de algo que é falado no contexto de uma relação intensa entre o pesquisador e a jovem. Essa relação de grande responsividade mútua, vínculo e troca afetiva permite que uma sugestão dessa natureza adquira impacto junto ao sujeito.
} 
que possui considerável potencial para dialogar com a singularidade dos sujeitos.

\section{REFERÊNCIAS}

Arrais, A. (2005). As configurações subjetivas da depressão pósparto. Para além da padronização patologizante. Tese de Doutorado Não Publicada, curso de Pós-Graduação em Psicologia, Universidade de Brasília, Brasília, DF.

Ayers, J. (2000). The Use of Alternative Therapies in the Support of Breastfeeding. Journal of Human Lactation, 16(1), 51 - 56.

Berthold, K. (2004). Breast milk components that may influence immunity. Journal of Gastroenterology Pediatric and Nutrition, 39, 554.

Cepicky, P., Pecena, M., Roth, Z., Stroufova, A. \& Sosnova, K. (1995). A successful inducement of prolactin secretion and an unsuccessful attempt to influence the luteinizing hormone secretion by a hypnotic suggestion of breastfeeding. The International Journal of Prenatal and Perinatal Psychology and Medicine. 7(3),303-307.

Duddridge, E. (2002). Using complementary therapies during the childbearing process. British Journal of Midwefery, 10(11), 699 704.

Erickson, M. H. (1952). Deep hypnosis and its induction. In L. LeCron (Org.). Experimental hypnosis (pp. 70 - 114). New York: Macmillan.

Erickson, M. (1958). Naturalistic techniques of hypnosis. The American Journal of Clinical Hypnosis, 1,3-8.

Erickson, M. (1983). Healing in hypnosis. The seminars, workshops and lectures of Milton Erickson. (vol I). New York: Irvington.

Erickson, M. (1985). Life reframing in hypnosis. The seminars, workshops and lectures of Milton Erickson. (vol II). New York: Irvington.

Erickson, M. (1986). Mind-body communication in hypnosis. The seminars, workshops and lectures of Milton Erickson. (vol III). New York: Irvington.

Erickson, M. (1992). Creative choices in hypnosis. The seminars, workshops and lectures of Milton Erickson. (vol IV). New York: Irvington.

Erickson, M. (1980). An introduction to the study and application of hypnosis for pain control. In M. Erickson \& E. Rossi (Orgs). The collected papers of Milton Erickson, MD. (pp. 237 - 245).

Erickson, M. \& Rossi, E. (1979). Hypnotherapy: an exploratory casebook. New York: Irvington.

Erickson, M. \& Rossi, E. (1980). Indirect forms of suggestion in hand levitation. In M. Erickson \& E. Rossi (Orgs). The collected papers of Milton H. Erickson, MD. (452 - 477). New York: Irvington.

Freud, S. (1996). Sobre a psicoterapia. (J. Salomão, Trad.). Edição standard das obras psicológicas completas de Sigmund Freud. (Vol VII, pp. 239 - 251). Rio de Janeiro: Imago. (Original publicado em 1905)
Gonzalez R. F. (2005). Pesquisa qualitativa de subjetividade. São Paulo: Thomsom

Golse, B. (2003). Sobre a psicoterapia pais-bebê: Narratividade, filiação e transmissão. (R. Aragão, Trad.). São Paulo: Casa do Psicólogo. (Original publicado em 2002).

Melchior, T. (1998). Créer le réel. Hypnose et thérapie. Paris: Seuil.

Montgomery, A. Hale, T. (2006). ABM Clinical protocol 15. Analgesia and anesthesia for the breastfeeding mother. Breastfeeding Medicine, 1(4), 271 - 277.

Nash, M. \& Barnier, A. (2008). The oxford handbook of hypnosis. Theory, research and practice. New York: Oxford University Press.

Neubern, M. S. (2001). Três Obstáculos Epistemológicos Para o Reconhecimento da Subjetividade na Psicologia Clínica. Psicologia: Reflexão e Crítica. 14(1), 241-252.

Neubern, M. (2004). Histórias que (não) curam: Sobre narrativas em hipnose clínica. Psicologia: Ciência e Profissão, 3, 58 - 65.

Neubern, M. (2005). A dimensão regulatória da psicologia clínica. O impacto da racionalidade dominante nas relações terapêuticas. Estudos de Psicologia, 10(1), 73-82.

Neubern, M. (2006). A subjetividade como noção fundamental de um novo paradigma. Em F. Gonzalez Rey (Org). Subjetividade, complexidade e pesquisa em psicologia. (pp. 53 - 79). São Paulo: Thomsom.

Neubern, M. (no prelo). Hipnose e dor: Proposta de metodologia clínica e qualitativa de estudo. Psico (USF).

Raysler, J. (1999). Alternative healing in nurse-midwifery practice. Journal of Obstetric, Gynecologic, \& Neonatal Nursing $8(2), 109-111$.

Rossi, E. \& Cheek, D. (1988). Mind-Body therapy. Methods of ideodynamic healing in hypnosis. New York: Norton.

Roustang, F. (1991). Influence. Paris: Minuit.

Tiran, D. (2005). Complementary therapies in maternity care: personal reflections on the last decade. Complementary Therapy in Clinical Practice, 11(1), 48-50.

Tiran, D. \& Chummun, H. (2004). Complementary therapies to reduce physiological stress in pregnancy. Nursing and Midwifery, 10(3), 162-167.

Zeig, J. (1994). Advanced techniques of utilization: an intervention, metamodel and the use of sequences, symptom words and figures of speech. In J. Zeig (Org). Ericksonian methods. The essence of the story. (pp. 295 - 314). Levittown: Brunner/Mazel.

Zeig, J. (2006). The virtues of our faults. In J. Zeig (Org). The selected papers of Jeffrey K. Zeig (vol I). (pp. 71 - 94). Phoenix: Zeig, Tucker \& Thiesen.

Recebido em 07/04/2009 Aceito em 18/11/2009
Endereço para correspondência:
Maurício da Silva Neubern. Campus Universitário Darcy Ribeiro, ICC, Sul, Departamento de Psicologia Clínica, Instituto de Psicologia, CEP 70910-900, Brasília-DF, Brasil. E-mail: mneubern@hotmail.com. 